\title{
Challenges of the Change of Decentralized Support Structures in Combination with Digitization Processes in the Student Life Cycle. RWTHonline the New Campus Management System of RWTH Aachen University
}

\author{
Sarah Grzemski \\ RWTH Aachen University \\ Aachen, Germany \\ grzemski@itc.rwth-aachen.de
}

\author{
Bernd Decker \\ RWTH Aachen University \\ Aachen, Germany \\ decker@itc.rwth-aachen.de
}

\begin{abstract}
The European Bologna Process, as well as a digital revolution in teaching worldwide, has prompted RWTH Aachen University (RWTH) to switch to a new campus management system (CMS) that all students (over 44,500) and most of the approximately 9,200 employees of RWTH will have to use by winter term 2018/19.

The introduction of the new CMS "RWTHonline" is an answer to the requirements of teaching digitization and the increased complexity of student lifecycle processes. Additionally, it is an opportunity to address the problem of too many different systems being in use at the university. However, it has various support, communication, and documentation challenges, particularly the need to reorganize decentralized support structures.

The latter challenge had initially only been marginally considered within the implementation project. However, the heterogeneous working methods, departmental structures and process understandings of the affected parties as well as the importance and complexity of the issue, called for the initiation of a sub-project solely dedicated to developing new support structures. Under the project management of the IT Center, all parties involved are working closely together to develop new accepted university-wide support structures. The paper presents the particular challenges of setting up new university-wide support structures within the context of the new CMS "RWTHonline" as well as possible solutions.
\end{abstract}

\section{CCS CONCEPTS}

- Applied computing $\rightarrow$ IT governance; Service-oriented architectures; Business rules;

\section{KEYWORDS}

decentralized support, cultural difference, process understandings, service process, reorganization, IT Service Management

\section{ACM Reference Format:}

Sarah Grzemski and Bernd Decker. 2018. Challenges of the Change of Decentralized Support Structures in Combination with Digitization Processes in

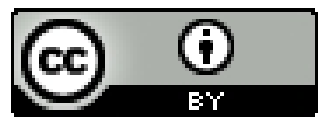

This work is licensed under a Creative Commons Attribution International 4.0 License.

(c) 2018 Copyright held by the owner/author(s)

ACM ISBN 978-1-4503-5582-7/18/10.

https://doi.org/10.1145/3235715.3235719 the Student Life Cycle. RWTHonline the New Campus Management System of RWTH Aachen University. In 2018 ACM SIGUCCS Annual Conference (SIGUCCS '18), October 7-10, 2018, Orlando, FL, USA. ACM, New York, NY, USA, 7 pages. https://doi.org/10.1145/3235715.3235719

\section{INTRODUCTION}

The Bologna Process presents European universities with a multitude of challenges that affect the design of study programmes as well as the fundamental organisation of higher education institutions. RWTH, as one of the largest technical universities in Europe, is also confronted with these challenges. In addition to reorganizing university-wide processes, RWTH has set itself the goal of introducing an integrated CMS [15]. This system should make it possible to meet the requirements of the Bologna Process for the student life cycle. The large number of systems previously used for campus management do not optimally support the modular structure of Bachelor's and Master's programmes. For the RWTH IT Center's IT-ServiceDesk (IT-SD), the introduction of a new integrated system means a change in the existing support processes and structures. New support, communication, and documentation processes and concepts must be developed as part of these changes. The "cultural difference" between the parties involved in this interdisciplinary project make finding a common ground and understanding especially challenging. The following paper describes the project "Reorganization of processes around examination performance and course event management including the introduction of an integrated software solution" ("PuL"). PuL is the comprehensive organizational and information technology response of RWTH to the challenges of the Bologna Process [15]. The focus lies on presenting the challenges for support structures that arise from the introduction of an integrated CMS. Possible solutions for these requirements are discussed. A special focus is placed on the recently established sub-project "Support" in which all parties are involved. Finally, a future outlook will be given.

\section{THE BOLOGNA PROCESS, RWTH AACHEN UNIVERSITY AND THE PUL PROJECT}

\subsection{University implications of the Bologna Process}

The consequences of the Bologna Declaration [5] can hardly be overestimated. Universities must initiate fundamental and long-term reform processes in view of the goals formulated in the declaration 


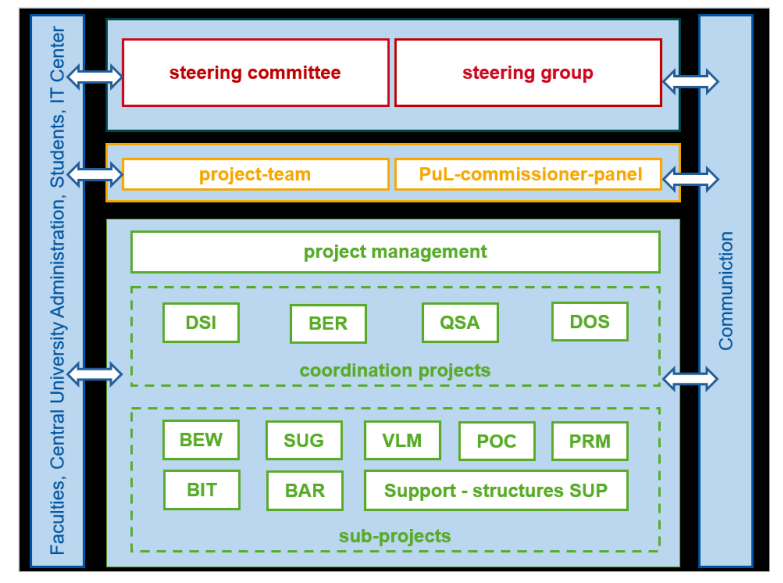

Figure 1: PuL project structure [15]

[10]. This reformation and restructuring of study-relevant structures presents an enormous increase in complexity for RWTH in the areas of study and teaching [15]. Several examination regulations and module descriptions have to be newly created. An additional challenge is the sharp increase of the number of students due the large number of high school graduates in 2013 when the German Abitur was shortened from 13 to 12 years [1]. In addition, the particularly pronounced interdisciplinarity of courses offered and the strong interweaving of research with economic interests at RWTH increase the organizational effort. The university-wide PuL project, which was launched in 2011 and is scheduled to be completed at the end of 2018, is concerned with overcoming these hurdles. The aim of this project is to support the reorganization of processes related to the degree programmes and their digitization by introducing a new CMS. This reformation means adjusting support processes and structures accordingly. This is a challenge that offers the opportunity to make these structures and processes more customer-friendly than ever before.

\subsection{The PuL Project: Structure and Goals}

The PuL project was commissioned by the rectorate of RWTH [15]. More than 100 members from different RWTH institutions are involved. Faculties, administrative units, student representatives and the IT Center work closely together to reorganize and digitize processes as well as introduce the new software. The project is divided into a steering level, the level of project management and the level of sub-projects and coordination (Figure 1). The sub-projects are responsible for the technical and functional issues. Coordination projects include quality assurance, the design of documentation and training, reporting and data migration.

With regard to the student life cycle, the project deals with the topics of examination performance management and course event management, application and admission as well as student and fee management. Corresponding processes become more transparent and optimized as part of their reorganization [3]. Based on the newly designed processes, a new integrated CMS will be gradually introduced by winter semester 2018/19 (WS2018/19). This system was acquired from TU Graz [12] and is called "RWTHonline". Up to now, RWTH has been working with heterogeneous IT systems as part of the student life cycle. While the organization of events is handled in the campus system of CAS AG, the examination and student management is handled via systems of HIS eG. These systems have now reached their technical limits. RWTHonline unifies these heterogeneous systems and will make complex procedures of data migration in the student life cycle [13] unnecessary in the long term. The new system was tested in pilot operation during winter semester 2017/18 (WS2017/18) and summer semester 2018 (SuSe2018) to ensure a safe and low-risk introduction. The members of two study programmes are participating in the pilot, namely Bachelor of Science in Chemistry and Master of Arts in Political Science [14]. Additionally, the application and fee management for all applicants and students was transferred to the new CMS in winter 2017/18. In order to provide a simple support channel for students, applicants and employees a central contact e-mail address was published at the start of WS2017/2018. This contact e-mail address forwards the requests to the IT Center's tickettool. During the pilot phase, it became clear that the topic of support, documentation and communication had not yet been firmly anchored in the project. The number of inquiries made via the contact e-mail address was approximately 3,000 in January and February 2018, an increase by $900 \%$ compared to the same months in 2017 [9]. As a result, the PuL project management decided to set up an additional sub-project in order to arrange university-wide support, documentation and communication processes.

\section{CHALLENGES OF INTRODUCING THE CAMPUS MANAGEMENT SYSTEM RWTHONLINE WITH REGARD TO SUPPORT}

The introduction of the new CMS presents the challenge of restructuring the entire support, documentation, and communication (technical/content-related) for RWTHonline. The involved departments of the RWTH IT Center, the Central University Administration (ZHV) and faculties must do this cooperatively - which represents an additional challenge. Existing processes and structures must be taken into account. The aforementioned scenarios identified three new types challenges for which cooperative work structures must be considered [6]:

- Formal challenges

- Work organization and communicative challenges

- Technical challenges

A special feature is a fourth area that can be described as a "cultural difference between disciplines". From previous experience, this "cultural difference" can be traced back to various factors [6], [4]:

- Organizational anchoring within a university (anchoring in a chair vs. anchoring in a central institution)

- Professoral (scientific) leadership vs. management in accordance with the administration

- IT services vs. [legal] administrative services

- Heterogeneous educational backgrounds of employees and the associated differences in ways of thinking and knowledge levels 
- Different interests of all parties involved (IT questions vs. questions of content)

- Different ways of dealing with change and the willingness to promote change.

It should be noted at this point that the establishment of the sub-project Support has created a framework that takes all those involved at the university into account and focuses precisely on the conflicts that arise as a result of the "cultural differences between disciplines". The analysis of the current support, documentation, and communication processes and structures helps to develop an understanding of how modern and customer-friendly processes and structures must look in the future. It must be considered, however, that these transformations result in considerable changes in work organization. This makes it necessary to consider the different working cultures and understanding of support. An important prerequisite for the Support sub-project is that there is currently no "secret plan" as to what the result should look like [4]. This openness supports the trust and willingness of all parties involved to develop modern support, documentation and communication processes and structures.

\subsection{Internal IT Center support structure}

The CMS is technically supported and operated by the RWTH IT Center. Within the IT Center, the following departments are involved: IT-SD, IT Process Support (IT-PFL) and Systems and Operations (SuB). IT-SD collects, processes and, if necessary as an answer cannot be given in 1st-level support, forwards support requests for all IT services of the IT Center to the corresponding specialist departments. The IT-SD was established in 2010 as part of the introduction of IT Service Management at the IT Center and serves as a single point of contact for all inquirers [7]. In order to guarantee quality-assured support, IT-SD operates a quality management system in accordance with DIN EN ISO 9001:2015, which was certified accordingly in 2016 as well as successfully reviewed in 2017 [11] and 2018. Prior to the establishment of the Support subproject, processes were defined for processing requests relating to the current CMS. These processes were constantly being developed in close coordination with the Process and Application Consulting group of IT-PFL. One of the measures taken was that the IT Center IT-Service-Management-Tickettool for RWTHonline stored corresponding services, partial services and teams for processing. The IT-PFL department is responsible for consulting and training on the CMS. In addition to consulting and training tasks, the IT-PFL department performs the following activities:

- IT process development, process design, requirements analysis, introduction, integration and further development of efficient and sustainable IT solutions

- Process support for campus management (CMS), e-learning and the RWTHApp

- Management and further development of central applications for the important business processes of RWTH together with the cooperation of partners in the ZHV and the faculties

Within the scope of the introduction of RWTHonline IT-PFL is responsible for the integration of existing data into the new system and the provision or development of interfaces to neighbouring systems. For example, room data must be migrated from the software for room booking via an interface to RWTHonline. IT-PFL also provides interfaces to databases in which the personal data of students and staff members are stored. In addition to this technical component, IT-PFL is again responsible for consulting, training and documenting RWTHonline in cooperation with Department 1 of the ZHV. The Systems and Operations department (SuB) is responsible for the regular operation of hardware and software systems and offers the following services, among others:

- Backup and archive

- Email and groupware

- Identity Management

Furthermore, SuB operates the CMS and the underlying server infrastructure and basic software. Due to the integrative tasks, support and operational structure of RWTHonline, different challenges arise for support, documentation and communication, which became very clear during the introduction of the system. On the one hand, it must be clarified how an internal IT Center support structure is set up. In short: Who talks to whom and when? Currently, incoming support requests from users (applicants, students and employees of the university) are initially processed in the IT-SD as requests based on the current IT Service Management processes. However, if a solution cannot be provided by the IT-SD, the request must be forwarded either to the SuB department or to the IT-PFL department. For this purpose, IT-SD has keyword lists at its disposal on the basis of which the queries are forwarded to the correct support team. In case a request cannot be classified with the help of these keywords, there are so-called default partial services to which default teams are assigned who then take care of the correct distribution. After one of the two departments has processed the request, the IT-SD usually communicates an answer to the user. This is important in order to reduce the burden of the speciality department staff and to create awareness for the support processes among the users. Direct contact of employees within the IT Center's specialist departments by inquirers should be avoided. In addition, this process leads to learning effects for IT-SD employees. Requests and their solutions are recorded by the IT-SD documentation team for future answers to similar requests. Another challenge is that the new system must also forward requests from the 2nd level units (SuB or IT-PFL) of the IT Center to the vendor of the campus management software (TU Graz). The following scenarios are possible for dealing with these requests:

Scenario 1: The employees of the IT-PFL and SuB departments contact the software vendor's support directly and receive the vendor's replies directly. A positive aspect of this scenario is that communication is very fast, and problems can be solved quickly. The disadvantage is that it is highly probable that the answers will not be documented, because the specialist department employees are often primarily active in the operative business and solutions are implemented quickly. However, this implementation is not linked to any documentation processes. In the long run, the lack of documentation does not increase the speediness of problem solution but slows it down as the same problem is repeatedly communicated to the vendor instead of being solved directly by means of documentation. 


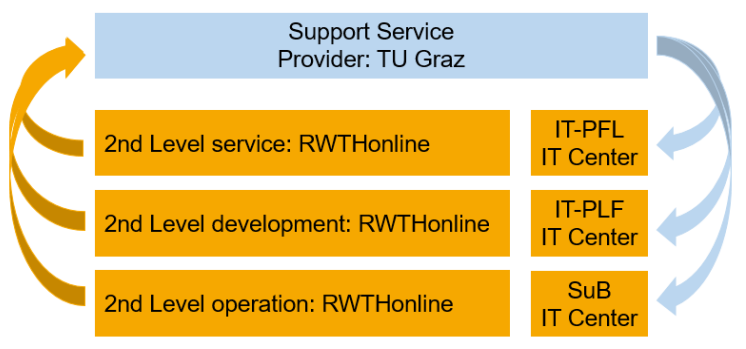

Figure 2: Scenario 1 internal structure [2]

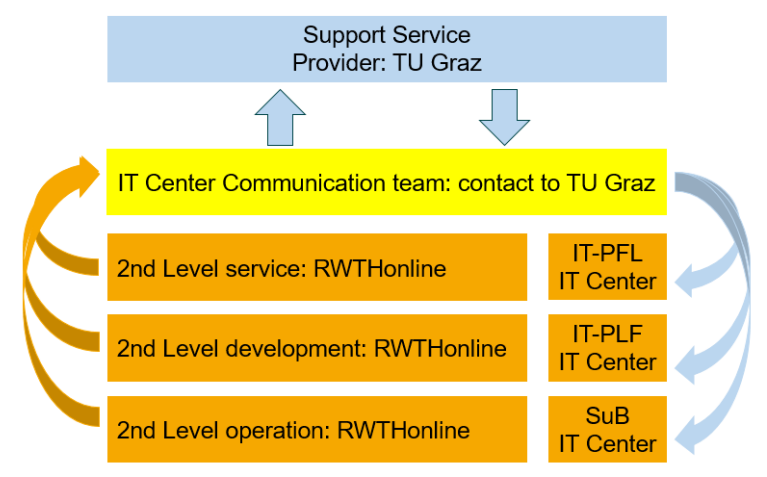

Figure 3: Scenario 2 internal structure [2]

Scenario 2: A team with members from all three departments is formed within the IT Center. Support requests to the vendor are forwarded by this team. If an answer is provided by the vendor, the team communicates the answer to the appropriate department of the IT Center. The advantage of this scenario is that knowledge is built up simultaneously in all three departments. This scenario also has disadvantages. The establishment of such a team initially generates an increased workload. It must also be determined in which department the team will be located and which employees will be partially released from work for the team. The intermediate instance introduced also causes delays in the communication of the response. For both scenarios it must also be discussed whether they can be extended to the facilities of the ZHV and, if applicable, faculties that also wish to make use of the support of the TU Graz.

Scenario 3: It is possible that there will be a mixture of the two scenarios, in which there is a communication team, but some previously defined actors are allowed to communicate directly with the TU Graz. These questions are also addressed in the sub-project Support. Currently it is not possible to give a final answer on who may/must speak to the vendor and when. In addition to the IT Center departments, other ZHV institutions such as the Central Examination Office (ZPA), the Student Registrar's Office as well as International Office and others are involved in processing support requests regarding the CMS. As a result, their existing RWTH support structures must also be reviewed in the Support sub-project.

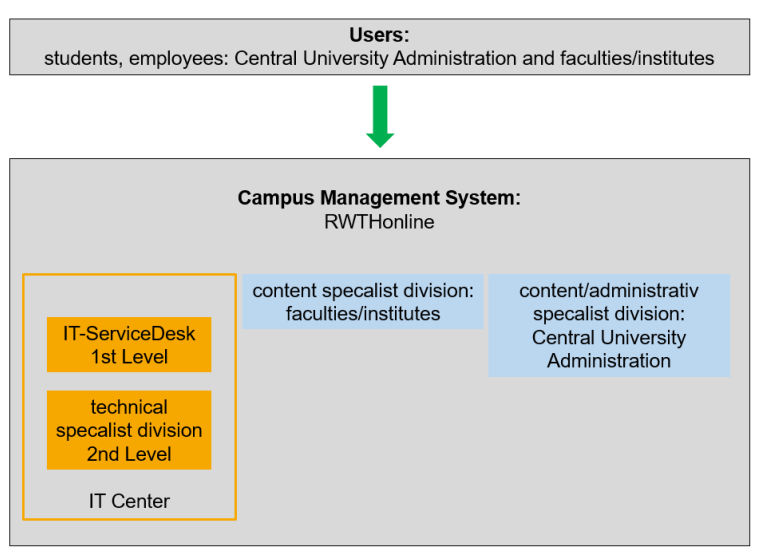

Figure 4: Support structure, modified after [2]

\subsection{The sub-project Support and RWTH-wide support structure}

Although the IT-SD is the single point of contact for IT support, neither it nor the IT Center does not provide comprehensive content and technical support for the existing CMS or for RWTHonline. This means that in addition to the IT Center, other ZHV institutions that also process support requests, e.g. the Student Registrar's Office or the Central Examinations Office, need to be involved. A simplified representation of the current situation is shown in (Figure 4)

The number of inquiries increased massively with the introduction of the new system. This is partly due to the fact that the users have not yet become accustomed to working in an integrated system. Additionally, the functionalities of the RWTHonline system are still changing very frequently. As a result, the application of the system as a whole requires a high degree of flexibility and willingness to familiarize oneself with it again and again at short notice. As a result of the publication of the central contact e-mail address, the vast majority of (often non-technical) inquiries by students and (mostly operational) inquiries by employees are addressed to the IT-SD. The resulting large volumes of requests cannot be handled by the IT Center alone - the need for cooperation became clear to all parties involved. The demands on employees and project members far exceed a solely technical understanding. It is much more important to ensure that empathic and communicative skills are available. In order to recognize and live the advantages of cooperation across facility boundaries, it is necessary to understand that it is not a matter of taking something away from someone. Rather it is making it clear that in the long term, quality assured support can only be provided through close cooperation [6]. It is therefore necessary to create a common understanding that it is efficent sense to work together. The achievement of the following goal of the sub-project Support is thus crucial:

- The creation of modern support structures in student lifecycle management for the best possible support of the various user groups (students, employees in the ZHV and in the faculties)

At the same time, the following strategic goals of RWTH are taken into account: 
- Excellence in teaching

- Increasing competitiveness in teaching

- Modern state of the art administration and IT services

In order to achieve these goals, the following key points have been defined [4]:

- Creation of a central e-mail address for all inquiries (technical and functional)

- Creation of common support structures and processes between the service providers involved (Dec 1.0, Dec 2.0, PuL team and IT Center)

With these objectives and cornerstones, it becomes clear that this is primarily an organizational development project which must be adequately supported and accompanied by all the institutions involved. The participants' agreement that it is a matter of developing consistent processes in the sense of the aforementioned goals and cornerstones was a milestone. The understanding and trust that the decision on the technical implementation is based on the processes defined in the Support sub-project must be particularly emphasized. Under these conditions, the Support sub-project management was transferred to an IT Center employee with a communications science background and a focus on process support. Within approximately 8 weeks, an interim solution was found that was coordinated between all parties involved. This solution supports the IT-SD in quickly identifying to which department or faculty of the university the request must be forwarded. Furthermore, it was defined how to proceed with incorrectly forwarded e-mails by the IT-SD to the ZHV, within the ZHV as well as back from the ZHV to the IT Center. This solution is only temporary, and no claim based on it can be made for a more comprehensive final solution. With the coming into effect of this interim solution, inquiries are forwarded by the IT-SD via e-mail to the relevant specialist department of the ZHV (unless otherwise agreed). The users will be informed by the IT-SD that the e-mail has been forwarded to and will replied to by the correct ZHV department. This is an anomaly for the IT-SD employees as they have to get used to regularly transferring requests via e-mail rather than -as per usualthrough the IT Service Management-(Ticket-)tool. The IT-SD only helps the customer directly in defined and clearly described cases. Requests that are obviously of a technical nature are always processed directly by the IT-SD or transferred to the 2nd level within the IT Center in the usual manner. Requests for which there is no regulation are also transferred to the 2nd level. Keyword lists are maintained to support the IT-SD in routing requests to the various points within the university. Since experience in supporting RWTHonline is still lacking, these keyword lists are not final but more of a first aid. The aim is to continuously enrich these keyword lists with support information so that all participating support units can expand their know-how and find solutions more quickly in the future. With increasing experience, it will then be decided step by step where the routing of requests needs to be optimized. It will also be defined how the IT-SD can support the specialist departments and how much of the request processing it can do directly. Queries involving the vendor are always handled via the IT Center's 2nd level. Requests that have to be answered by the faculties are transferred from the 2nd level of the IT Center to an appropriate team via the (ticket-)tool. This too is a special feature, and perhaps a step towards a simple university-wide solution. Prior to the establishment of the Support sub-project, faculty staff were not involved in the development of university-wide support, documentation and communication processes. What is striking about this approach is that media breaks occur between the IT Center and the ZHV, which can lead to communication problems. Compliance with the agreed procedures is essential. Challenges that all participants must be aware of:

- Due to the media breaks (in case the request is forwarded to another institution) there is no complete history of the request and solution process. This makes it difficult to trace the problem and document the solution.

- The transitional solution does not permit continuous documentation and makes it more difficult to provide support in the event of check backs from the inquierer.

- The history of the inquirers is not summarized and thus the danger of duplication and misunderstandings is increased.

- Inquiries from employees are processed accordingly making it especially important that ZHV and 2nd level IT Center do not circumvent the IT-SD.

- Due to the lack of documentation opportunities of organizational learning are low.

Currently, however, the interim solution is the "lowest common denominator" for the Support sub-project and all parties involved have agreed to this approach. To support the long-term strategy of providing quality-assured, modern, and easy-to-use support for RWTHonline, the Support sub-project group is already working intensively on more sustainable solutions. This means that longterm support, documentation and communication structures for effective cooperation across institutions are being developed in parallel with transitional solutions. The experience that the IT-SD has already gained in other university-wide projects is helpful here. However, it can only be brought to bear very cautiously due to the cultural differences between the institutions [6]. The following describes a possible scenario that could contribute to achieving the objectives of the Support sub-project.

In order to establish and establish modern support for both students and staff in the ZHV and the faculties, it is conceivable to centralise (as far as possible) many contact channels to a single point of contact. In detail, this means that existing support structures are built upon and, if necessary, expanded. The IT-SD is established and accepted as a single point of contact for questions to IT Centers. This has the advantage that the requester does not have to think about whom to contact. Based on the experiences from other cooperations and projects, all inquiries to RWTHonline will then be received centrally in IT-SD. There they are classified and categorized. If the IT-SD cannot answer the question, it will pass it on to the institution or department responsible for processing via a uniform technical solution (e.g. the IT Service Management-Tool of the IT Center). This ensures that the problem history (due to communication without media discontinuity) remains comprehensible for all parties involved. It must also be taken into account that learning effects are quickly realized in this way. IT-SD has a comprehensive knowledge of the various, recurring problem cases and their solutions and is able to answer frequently recurring requests directly. At the same time, the use of a central technical solution 


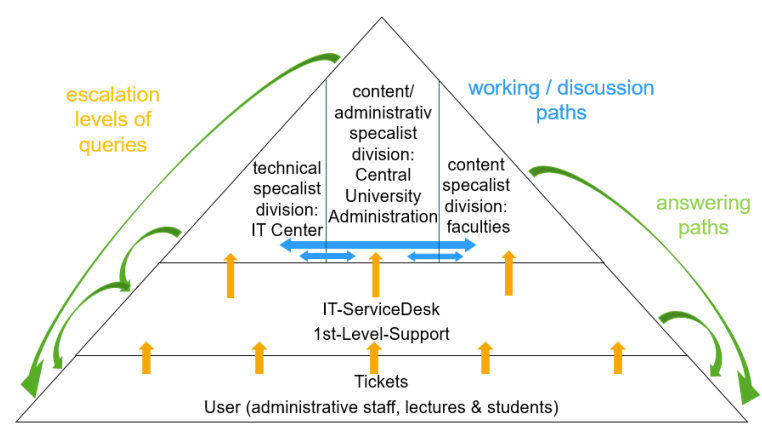

Figure 5: Support Pyramide, extended to [6]

ensures that both faculties and central facilities can communicate with each other and with enquirers without media discontinuity. It must be taken into account that communication with the inquirer is and remains possible through the various specialist departments. In many cases it makes sense and is necessary for departments and faculties to speak directly with the inquirer. If this is implemented via defined channels and with coordinated tools, nothing stands in the way. Communication between different departments is also possible as long as defined processes are observed [6]. In Figure 5 the yellow arrows represent the communication path of incoming requests, the green arrows the communication path of the responses, the blue arrows indicate communication structures between the specialized divisions.

Requests that cannot be resolved directly by IT-SD are either forwarded to a department of the IT Center or directly to the responsible institution. In the case of inquiries that fall within the scope of the IT Center, the answer is communicated via the IT-SD. This model provides for the answers of the participating institutions to be communicated to the inquirers without detour via the IT-SD. However, there are regular exchange appointments between the IT Center and the participating institutions in order to identify requests that can be answered directly by the 1 st level of the IT Center. These agreements between IT-SD and the ZHV institutions are recorded in support agreements. These are used to document who is responsible for which requests. A modification of the current support model described in Figure 5 is that the answers of the ZHV facilities are communicated via the IT-SD. This modification enables IT-SD to build up knowledge more quickly and adapt the documentation. The procedure described above relieves all participating facilities, since defined requests can be answered directly by the IT-SD. This will provide a quicker response to enquirers. This approach is already being successfully implemented as part of the "Research Data Management" project at RWTH [6]. However, this requires the willingness of the participating institutions to provide a single technical solution (e.g. the IT Center's IT Service Management (Ticket-)tool). In addition to the willingness to change existing working methods with new tools, the introduction of a new technical solution, the tickettool, also entails considerable costs. In addition to acquisition costs, both operating costs and training costs are incurred. As the example of the introduction of RWTHonline shows, the reluctance founded on habit in the form of acceptance problems must also be expected [8]. These problems often seriously prolong the introduction process of new software tools and in the context of RWTHonline would mean further burdens for the employees involved in support. By setting up the central support e-mail address, an essential prerequisite has already been met.

a for the centralized processing of all RWTHonline-specific inquiries and

b for the dismantling of parallel structures between IT-SD, ZHV and IT Center 2nd level.

As with the internal IT center support structures, no final decision has yet been made.

\section{CHALLENGES OF NEW SUPPORT STRUCTURES FOR 1ST LEVEL SUPPORT}

Changes to the internal IT Center and RWTH support structure affect the internal organization of the IT-SD. With the introduction of RWTHonline, 1st level support faces several major challenges:

1 Flexible adaption of IT-SD employees to short-term changes in processes and structures.

2 Agile adaption of support, documentation and communication structures as well as transfer to IT-SD internal processes

3 Understanding of the functionalities and connections of the new system and willingness to learn (requires training of employees and creation of support-oriented documentation).

4 Ensuring support, documentation and communication for two systems (old and new) as they will be in dual operation and parallel use during the pilot phase

5 Mutiple communication interfaces to other divisions in the IT Center and the ZHV.

It is therefore essential to document all changes promptly and appropriately, to communicate them and to incorporate them into the employees' training within the IT-SD. These tasks represent a significant additional burden on the IT-SD. In order to meet these requirements, two IT-SD employees have been assigned to internal documentation, communication, and training of all changes resulting from the introduction of RWTHonline. One of these employees is also a member of the Support sub-project. Both employees work very closely with the IT-PFL department and the PuL project group. The close exchange between the IT-SD and the 2nd level departments of the IT Center is currently a central point to achieve the goal of quality-assured support for productive operation in WS2018/19. It should be emphasised that particular importance was attached to pedagogical and organizational skills when filling these positions. Both employees can therefore function as a communicative and didactic interface between different users, ZHV institutions and sub-projects and as an integral part of the definition of support processes.

\section{OUTLOOK}

The introduction of the new CMS RWTHonline is based on the requirements of the Bologna Process for RWTH. At the same time it offers the opportunity to integrate the current (problematic) use of several systems into a single new system. This development does not only result in major technological challenges but rattles 
processes and structures throughout the entire institution. A common understanding of a defined service quality that meets user requirements must be created between very different "specialist cultures". It is thus crucial to deal with the specific challenges for support, documentation, and communication during the introduction of the new system. No ready-made solutions to meet these challenges are available. Instead, short- and long-term solutions are currently being developed in the Support sub-project in close cooperation between all parties involved. The IT-SD is significantly involved in this in order to contribute its experience from other cross-institutional projects to the process. Representatives of the IT-SD partake in important project meetings in order to collect important information for their department. Additionally, they actively participate in the development of support, communication, and documentation concepts in the Support sub-project. Most likely, establishing new processes and structures will not be completed with the end of the pilot operation and go-live. The developed concepts will have to be continually evaluated and, if necessary, adapted. As a long-term goal or vision, the quality of service for the users (e.g. students and employees) must be brought into focus. Concretely, this means that there is a central point of contact for all inquiries regarding RWTHonline. Not only user requests but also requests to the software vendor by the IT Center and ZHV departments involved in RWTHonline are to be handled via this single point of contact. The advantage of using a single ticket system or technical solution is that all inquiries can be documented in detail without media breaks and can be traced if required. Especially in the case of staff turnover within a specialist department, it is necessary to record and reuse knowledge that has been built up wherever possible. The first steps to pursue the long-term goal have already been made by setting up a central e-mail address for RWTHonline and introducing a cooperative transitional solution. It is crucial to continually discuss and evaluate these further by all parties involved. The sub-project Support addresses the challenges of developing a concept for centralized support.

\section{REFERENCES}

[1] 2013. Annual Report. Retrieved January 28, 2018 from http://www.rwth-aachen. de/global/show_document.asp?id=aaaaaaaaaavznqa
[2] Markus Baum, Ingo Hengstebeck, and Sarah Grzemski. 2017. Herausforderungen fuer den Support bei der Einfuehrung eines neuen Campus-Management-Systems am Fallbeispiel RWTHonline. In INFORMATIK 2017 (Lecture Notes in Informatics (LNI)), M. Eibl and M. Gaedke (Eds.), Vol. P-275. Gesellschaft fãijr Informatik e.V., Gesellschaft fuer Informatik e.V., Bonn, 1689-1701. https://dl.gi.de/bitstream/ handle/20.500.12116/480/paper07.pdf?sequence $=1$ \&isAllowed $=y$

[3] Linda Campo. 2011. Process Analysis and Reorganization. Retrieved March 8, 2018 from http://www.rwth-aachen.de/cms/root/Studium/Lehre/PuL-Projekt/ $\sim \mathrm{dxln} /$ Prozessanalyse-und-Reorganisation/?lidx $=1$

[4] Joerg Dautzenberg. 2018. Supportstrukturen RWTHonline. Vorschlag zur Einrichtung eines Teilprojektes, unpublished.

[5] Staendige Konferenz der Kultusminister der Laender in der Bundesrepublik Deutschland. 1999. Der Bologna-Prozess. Retrieved January 28, 2018 from https://www.kmk.org/themen/hochschulen/ internationale-hochschulangelegenheiten.html

[6] Sarah Grzemski and Ingo Hengstebeck. 2017. Future challenges for qualityassured IT support through cooperative structures. In BOOK OF PROCEEDINGS EUNIS 23rd Annual Congress Shaping the Digital Future of Universities, European University Information Systems Organization (Ed.), Vol. 23. European University Information Systems Organization, Muenster Germany, 2-15. https:/doi.org/10. $17879 / 21299722960$

[7] Sarah Grzemski, Ingo Hengstebeck, and Christian Bischof. 2011. Einfuehrung eines Service Desk am Rechen- und Kommunikationszentrum der RWTH Aachen University. In ALLGEMEINE ASPEKTE ZUR PROZESSORIENTIERTEN HOCHSCHULE, Andreas Degewitz und Frank Klapper (Ed.). Deutsche Initiative Fuer Netzwerkinformation E.V., Bock + Herchen Verlag, Bielefeld/Cottbus Germany, 181-198. https://dini.de/fileadmin/docs/Prozessorientierte_Hochschule 2011.pdf

[8] Roger Haeussling. 2014. Technologiesoziologie. Nomos Verlagsgesellschaft, BadenBaden Germany.

[9] Sarina Naber and Sabrina Baki. 2018. IT-ServicDesk Annual Report 2017.

[10] Sigrun Nickel. 2011. Zwischen Kritik und Empirie -Wie wirksam ist der BolognaProzess? 148 (2011), 8-17.

[11] Martin Pieters, Ingo Hengstebeck, and Sarah Grzemski. 2017. Einf Ãijhrung eines zertifizierten QualitÃdtsmanagementsystems im IT-ServiceDesk des IT Centers der RWTH Aachen University. In 10. DFN-Forum Kommunikationstechnologien (Lecture Notes in Informatics (LNI)), P. MÃijller, B. Neumair, H. Raiser, and G. Deo Rodosek (Eds.), Vol. P-271. Gesellschaft fã ijr Informatik e.V., Gesellschaft fãijr Informatik e.V., Bonn, 77-87. https://dl.gi.de/bitstream/handle/20.500.12116/480/ paper07.pdf?sequence $=1 \&$ isAllowed $=y$

[12] RWTHonline-Team. 2011. Future RWTH Aachen Campus Management System from TU Graz. Retrieved April 8, 2018 from http://www.rwth-aachen.de/cms/root/Studium/Lehre/PuL-Projekt/ PuL-Meldungen/ hgii/Kuenftiges-Campus-Management-System-fuer/?lidx=1

[13] RWTHonline-Team. 2011. What is RWTHonline? Retrieved March 8, 2018 from http://www.rwth-aachen.de/cms/root/Studium/Lehre/PuL-Projekt/ dxla/ RWTHonline/?lidx $=1$

[14] RWTHonline-Team. 2017. RWTHonline in Pilot Operation. Retrieved March 8, 2018 from http://www.rwth-aachen.de/cms/root/Studium/Lehre/PuL-Projekt/ RWTHonline/ mwej/RWTHonline-im-Pilotbetrieb/?lidx $=1$

[15] PuL Project Team. 2011. PuL-Projekt. Retrieved March 28, 2018 from http: //www.rwth-aachen.de/cms/root/Studium/Lehre/ djla/PuL-Projekt/?lidx=1 